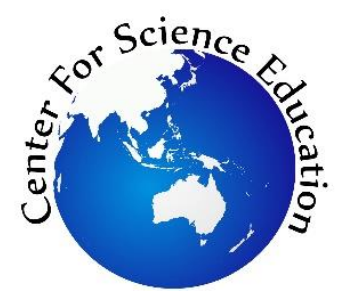

Tersedia online di EDUSAINS

Website: http://journal.uinjkt.ac.id/index.php/edusains

EDUSAINS, 13(1), 2021, 46-56

Research Artikel

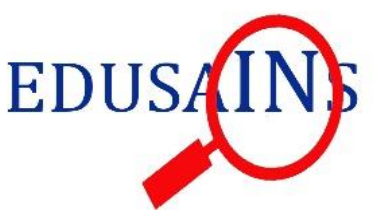

\title{
PENINGKATAN PEMAHAMAN KONSEP SISWA MELALUI MODEL PEMBELAJARAN IPA BERBASIS PHYSICS EDUCATION TECHNOLOGY-PROBLEM SOLVING
}

\author{
IMPROVING STUDENT'S CONCEPT UNDERSTANDING THROUGH SCIENCE LEARNING MODEL BASED \\ OF THE PHYSICS EDUCATION TECHNOLOGY-PROBLEM SOLVING
}

\author{
Florida Doloksaribu*, Triwiyono \\ Universitas Cenderawasih, Indonesia \\ floridadolok@gmail.com
}

\begin{abstract}
This study aims to determine the increase in understanding the concept of science material and the ability to experiment in a virtual context of energy and its changes in students of SMPN 13 Jayapura. This science learning model, PhETProblem Solving on students needs to obtain models and teaching materials that were more effectively used. The learning model is validated based on the suitability of indicators and material, legibility, and the suitability of assignments and exercises at an average value of 85.75 , which means it is very feasible to use. Participants consisted of a control class and an experimental class. The pretest and post-test results were analyzed based on the $N$-gain test; the experimental class dominated the high and medium categories at $30 \%$ and $70 \%$, conventional class $27 \%$ and $46 \%$. The implementation science learning model in context the energy context and its changes based on PhET-PS shows an increase in concept understanding and virtual experimental abilities. Based on the independent sample statistical test, it shows that there is a significant difference between the control class and the experimental class (sig. 2-tailed <0.5). Student responses to the PhET-PS learning model were very positive.
\end{abstract}

Keywords: improved understanding concept; physics education technology; problem solving

Abstrak

Penelitian ini bertujuan untuk mengetahui peningkatan pemahaman konsep materi IPA dan kemampuan eksperimen secara virtual konteks energi dan perubahannya pada siswa SMPN 13 Jayapura. Model pembelajaran IPA ini berbasis PhET-Problem Solving sesuai kebutuhan siswa guna mendapatkan model dan bahan ajar yang lebih efektif digunakan. Model pembelajaran divalidasi berdasarkan kesesuaian indikator dan materi, keterbacaan, dan kesesuain tugas- tugas dan latihan pada nilai rata-rata sebesar 85,75 artinya sangat layak digunakan. Partisipan terdiri dari kelas kontrol dan kelas eksperimen. Hasil pretes dan postes dianalisis berdasarkan uji N-gain, pada kategori tinggi dan sedang didominasi kelas eksperimen yaitu 30\% dan 70\%, kelas konvensional 27\% dan 46\%. Model pembelajaran IPA konteks energi dan perubahannya berbasis PhET-PS yang diimplementasikan menunjukkan terjadi peningkatan pemahaman konsep dan kemampuan eksperimen virtual. Berdasarkan uji statistik independent sampel menunjukkan terjadi perbedaan yang signifikan antara kelas kontrol dan kelas eksperimen (sig.2-tailed < 0,5). Tanggapan siswa terhadap model pembelajaran PhET-PS adalah sangat positif.

Kata Kunci: peningkatan pemahaman konsep; fisikal teknologi pendidikan; pemecahan masalah

Permalink/DOI: http:// doi.org/10.15408/es.v13i1.20003 


\section{PENDAHULUAN}

Pendekatan pembelajaran berbasis teknologi sudah menjadi tuntutan dunia pendidikan saat ini, disebabkan kemampuan teknologi peserta didik, akan lebih mampu mengatasi berbagai permasalahan. Pandangan terhadap kualitas pendidikan harus menjadi modal utama yang dapat digunakan sebagai sebuah konsep absolut dan idealisme yang tidak dapat dikompromikan. Guru dituntut profesionalitasnya sesuai dengan tujuan pembelajaran (Sallis Edward, 2006). Profesional guru dalam pembelajaran memberikan pemahaman yang lebih mudah kepada siswa. Guru yang professional harus dapat menangani berbagai permasalahan pembelajaran yang dihadapi (Avalos, 2011).

Berdasarkan profesionalitas, guru harus mengembangkan diri dalam bidang pembelajaran berbasis teknologi. Bagian teknologi pembelajaran saat ini sudah menjadi ranah pembelajaran yang dilakukan guru dan terpatri di pemikiran dan perlakuan agar tercapai peningkatan mutu sesuai era perkembangan pendidikan berbasis digital dan sains (Nursa'adah et al., 2018).

Sebagaimana halnya perkembangan teknologi pembelajaran dalam berbagai metode, maka para tenaga pendidik harus dapat menjadi pelopor penggerak investasi stakeholder pendidikan. Melalui penelusuran pengguna internet di berbagai daerah pedalaman Indonesia, wilayah khususnya Papua masih kesulitan mengaksesnya secara kontinyu. Hal ini mengakibatkan pelaksanaan pembelajaran berbasis teknologi internet tidak maksimal menggunakan teknologi tersebut. Padahal bagian ini harus dapat dimanfaatkan sebagai modal pengembangan model, metode, atau pendekatan Proses Belajar Mengajar (PBM) yang terkoneksi dengan aplikasi internet yang sudah diakses (Louis Major,et al 2021).

Fenomena permasalahan lainnya yang ditemukan di Papua yaitu dalam model pembelajaran IPA di Sekolah Menengah umumnya masih banyak yang belum menggunakan sistem pembelajaran berbasis virtual. Kondisi ini merupakan hal yang lumrah dibanyak sekolah di Papua. Sementara itu ketidakmaksimalan fasilitas pembelajaran IPA berbasis praktikum laboratorium, berdampak pada kurang maksimalnya pemahaman konsep siswa pada materi IPA. Hal ini disebabkan banyak fasilitas laboratorium yang kurang memadai.

Saat ini peranan teknologi pada ilmu pengetahuan secara khusus bidang eksperimen, telah sangat luas dimanfaatkan. Pada saat ini disebut sistem era industri 4.0, dimana segala sesuatunya dikaitkan dengan sains teknologi digital. Memahami kondisi pendidikan, khususnya model pembelajaran yang berbasis eksperimen, tidak selalu menggunakan laboratorium fisik sebagai satu-satunya media PBM yang digunakan. Model pembelajaran harus mengikuti perkembangan zaman dan mengikuti tantangan yang ada (Anderson \& Krathwohl, 2010).

Perkembangan era digital saat ini sudah dimanfaatkan untuk meminimalkan kondisi-kondisi laboratorium yang tidak memadai. Model pembelajaran konvensional, dengan laboratorium tidak selalu memadai merespon pembelajaran IPA secara khusus pada sekolah dan daerah tertentu. Hal ini disebabkan banyak kendala yang mungkin dihadapi, seperti ketidaktersediaan alat dan bahan, ketidaklengkapan fasilitas gedung dan lain-lain. Oleh sebab itu, melakukan pembelajaran IPA di kelas dapat terhubung dengan proses prosedural laboratorium yang berbasis digital komputer, sehingga makna pembelajaran IPA yang terhubung dengan teknologi virtual dapat berjalan dengan baik sesuai dengan prinsip pendidikan IPA yaitu teori dan praktikum (Doloksaribu \& Triwiyono, 2020). Hal ini terbukti pada penelitian Tuysuz (2010) yang dapat meningkatkan efektifitas pembelajaran kimia dalam peningkatan pemahaman konsep menggunakan Laboratorium virtual.

Proses belajar dan mengajar diusahakan dapat menyenangkan peserta didik. Rendahnya minat dan pemahaman siswa akan konsep sains yang telah dijelaskan oleh guru dengan metode pengajaran ceramah, membuktikan bahwa siswa tidak tertarik lagi pada model pendekatan ini. Maka diharapkan guru dapat menggunakan model-model pendekatan yang berbasis teknologi, agar siswa dapat lebih interaktif terhadap materi yang diterima misalnya seperti penggunaan Physics Eduction Technology simulation (Moore et al., 2014). 
Physics Eduation Technology (PhET) merupakan simulasi interaktif terhadap fenomena fisik berbasis riset yang dikembangkan oleh lisensi Colorado USA. Melalui pendekatan berbasis riset, diyakini para peserta didik dapat menghubungkan fenomena kehidupan nyata dan ilmu yang mendasarinya, sehingga dapat memperdalam pemahaman dan meningkatkan minat terhadap ilmu sains. Prinsip-prinsip PhET didasarkan pada penelitian tentang bagaimana siswa belajar (Bransford et al., 2000). Hasil dari wawancara simulasi proses $\mathrm{PhET}$, telah dapat secara efektif menggantikan peralatan laboratorium yaitu yang disebut dengan laboratorium virtual, serta dapat meningkatkan pemahaman konseptual siswa (Habibi H, Jumaidi J, 2020) . Melalui kondisi tersebut, pemanfaatan PhET dalam pembelajaran harus tergantung pada tujuan pembelajaran yang dikembangkan. PhET masih difungsikan pada simulasi atau kombinasi simulasi antara materi pembelajaran dan peralatan yang nyata. PhET simulasi telah memberikan aspek pengetahuan seperti mengetahui aktivitas dan respon melalui pemahaman siswa terhadap teknologi tersebut (D. P. Sari et al., 2018).

Beberapa penelitian yang menggunakan pendekatan PhET dalam sistem pembelajaran, telah menunjukkan peningkatan yang signifikan terhadap kemampuan berpikir kreatif siswa. Pendekatan berbasis konvensional yang dibandingkan PhET sudah sangat jauh tertinggal, akibat model-model yang dilakukan tidak lagi selalu dapat merangsang berpikir kreatif peserta didik (Supurwoko et al., 2017). Pendekatan simulasi jauh lebih baik dibandingkan dengan pendekatan konvensional di bidang pembelajaran IPA. Menurut penelitian yang dilakukan oleh (D. K. Sari et al., 2017), bahwa pembelajaran IPA terpadu melalui lembar kerja peserta didik sebagai penunjang PhET, dapat meningkatkan hasil belajar dan pemahaman konsep siswa. Melalui fenomena-fenomena di atas, PhET telah memberikan kontribusi yang baik kepada peningkatan kualitas pembelajaran sains (Cathlene T.B. \& Vida A.A., 2018). Namun, melalui keseluruhan penelitian berbasis PhET, masih lebih cenderung menggunakan PhET sebagai media pembelajaran yang berdiri sendiri dengan materi pembelajaran, sehingga bagi siswa dengan tingkat klasifikasi di bawah, belum maksimal memahami
PhET sebagai bagian dari konsep dan eksperimen secara utuh.

Model rekonstruksi yang dikembangkan oleh (Duit, 2007) menjadi salah satu cara memperbaiki kualitas pendidikan. Rekonstruksi model didaktis atau model education reconstruction (MER) digunakan peneliti untuk menghubungkan peningkatan kualitas pendidikan dan profesionalisme tenaga pendidik, karena penggunaan MER mengembangkan kerangka teoritis pembelajaran yang bermanfaat sesuai dengan keinginan (Duit et al., 2012). MER mempunyai hubungan yang erat pada penelitian pendidikan dengan tiga struktur utama yaitu : (1) konten sains dan signifikan pendidikan berupa konten IPA, (2) studi empiris pada pemahaman siswa (perspektif peserta didik) terhadap materi, (3) bahan instruksional sebagai penggerak praktek pembelajaran, sehingga mampu meningkatkan kemampuan pemahaman konsep IPA (Doloksaribu, et al., 2014).

Fitur PhET simulasi berbentuk virtual mendorong pembelajaran untuk eksplorasi sesuai dengan prinsip desain sains. Simulasi menjadi sebuah alat produktif dalam pembelajaran bagi siswa. Integrasi simulasi PhET sebagai fitur yang unik ini tidak tersedia pada sebagian besar alat pembelajaran lainnya seperti media interaktif, animasi, atau umpan balik dinamis. Oleh karena itu, laboratorium virtual simulasi merupakan media yang digunakan untuk membantu memahami suatu pokok bahasan dan dapat memberi solusi keterbatasan atau ketiadaan perangkat laboratorium.

Guru mengarahkan penggunaan PhET kepada siswa dengan laboratorium virtual agar materi atau konsep ilmu yang diberikan dapat tersampaikan dengan baik. Penggunaan PhET bukan sekedar permainan game semata, namun ada unsur praktek ilmu. Sehingga guru harus memahami terlebih dahulu konsep ilmu dari materi sains yang diberikan, agar PhET dapat efektif penggunaannya. Selain itu guru dapat memberikan tugas rumah kepada siswa dengan menghubungkan simulasi yang ada dalam PhET. Penggunaan PhET sangat efektif pada pembelajaran dari tingkat dasar, sampai pendidikan tinggi (Kriek \& Stols, 2010). Hal inilah menjadi dasar salah satu arah 
merekonstruksi pembelajaran IPA berbasis PhET pada konteks energi dan perubahannya.

Kemampuan menganalisis masalah diintegrasikan ke dalam simulasi PhET untuk mencari solusi terhadap permasalahan. Bersamaan dengan pemecahan masalah, pengambilan keputusan merupakan keputusan yang terbaik atau yang terburuk dari banyak alternatif sebagai penentu solusi dengan resiko minimum terhadap suatu pilihan (Stiggins, 2005). Pola pembelajaran berbasis $\mathrm{PhET}$ simulasi perlu diberikan pada siswasiswa untuk meningkatkan pemahaman konsep dengan laboratorium virtual yang menggunakan kemampuan berpikir pemecahan masalah (Clark \& Chamberlain, 2014). Konstruksi model pembelajaran IPA Berbasis Physics Eduction Technology Problem Solving (PhET-PS) mengarahkan peserta didik pada era industri 4.0, untuk dapat meningkatkan pemahaman konsep melalui eksperimen laboratorium virtual didasari pada permasalahan yang mudah ditemukan disekitarnya untuk mencari solusi. Sehingga pola integrasi PhET-PS pada penelitian ini dapat dirangkai seperti gambar 1.

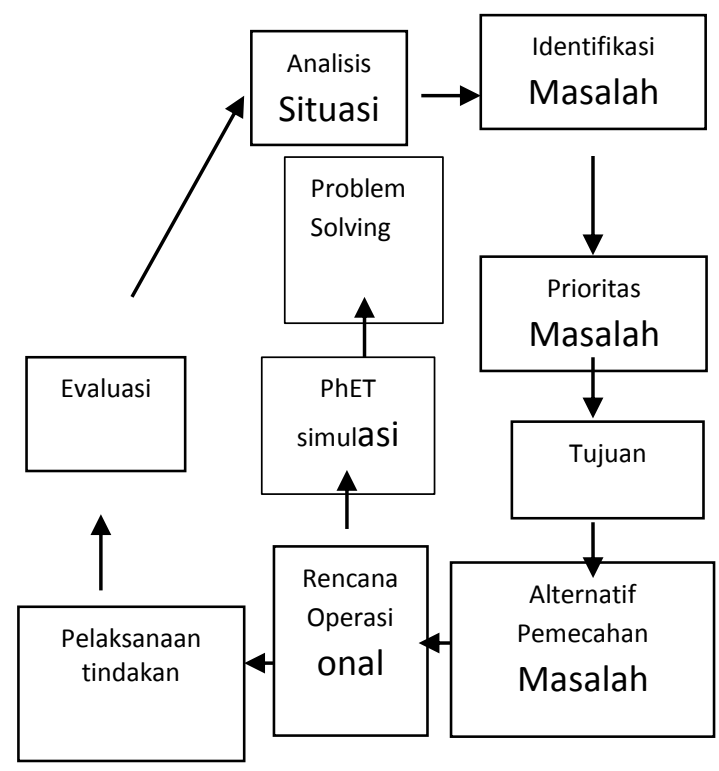

Gambar 1. Penggabungan PhET Problem Solving (Doloksaribu, F., 2020)

Berdasarkan permasalahan terbatasnya internet, pemanfaatan fasilitas laboratorium di sekolah-sekolah Papua, rendahnya minat siswa dalam pelajaran IPA, serta pentingnya IPA dalam melatih siswa mencari solusi dalam permasalahan, maka peneliti mencari alternatif solusi guna meningkatkan kemampuan siswa dalam memahami konsep IPA. Rekonstruksi materi ajar dengan PhET berbasis problem solving dibuat untuk mempermudah siswa memahami konsep melalui operasi simulasi. Sehingga dengan penelitian ini menjadi terobosan baru rekonstruksi pembelajaran IPA virtual menggunakan operasional PhET melalui problem solving sebagai cara memecahkan permasalahan proses belajar mengajar di Papua untuk meningkatkan pemahaman siswa pada konteks energi dan perubahannya.

\section{METODE}

Penelitian ini merupakan penelitian eksperimen implementasi model pembelajaran IPA yang telah didesain berdasarkan konstruksi model education reconstruction. Analisis pendahuluan didasarkan pada kebutuhan siswa melalui studi observasi dan perkembangan teknologi pembelajaran saat ini yaitu PhET-Problem solving, klarifikasi materi subjek dan implementasi model.

Validasi model pembelajaran dilakukan untuk mengetahui kelayakan model dan bahan ajar melalui validasi expert judgement (Roger Cooke, 2014), dimana tim ahli dengan bidang keahlian pada keterkaitan antara material dan indikator PhET-PS, kesesuaian ilustrasi dan gambar, serta keakuratan latihan dan soal melalui rumus: $\%$ expert judgement = $\frac{\text { Banyak butir komponen yang telah disetujui panel }}{\text { Lbutir komponen }} \mathrm{X}$ $100 \%$

Partisipan terdiri dari 30 orang siswa sekolah menengah pertama Negeri 13 Jayapura, terbagi dalam dua kelompok yaitu kontrol dan eksperimen.Teknik pengambilan sampel adalah sampling jenuh berdasarkan ketersediaan kelas (Sugiyono, 2011)

Pengumpulan data berdasarkan nilai pemahaman konsep dan kemampuan mengoperasionalkan PhET yang dihubungkan dengan berbagai permasalahan dan pemecahannya. Hasil pretes dan postes berdasarkan analisis $\mathrm{N}$-gain (Hake, 1999).

Penentuan perbedaan nilai postes kelas kontrol dan kelas eksperimen berdasarkan uji normalitas data melalui analisis dua sampel 
independen t-tes dengan menggunakan model analisis SPSS 21 (Sundayana, 2014). Sedangkan untuk mengetahui tanggapan siswa terhadap implementasi model melalui analisis hasil tanggapan siswa dengan pemberian kuesionar skala sikap Likert.

\section{HASIL DAN PEMBAHASAN}

Hasil tahapan rekonstruksi modul IPA konteks energi dan perubahannya berbasis PhETPS, dengan analisis materi subjek digambarkan pada gambar diagram 2. Proses MER merupakan dasar tahapan rekonstruksi modul pembelajaran IPA yang digunakan. Adapun hasil klarifikasi materi subjek energi dan perubahanya direkonstruksi dengan model PhET berbasis indikator problem solving. Setelah klarifikasi materi subjek, dilakukan penggabungan konten materi dengan indikator-indikator berpikir problem solving seperti 1) analisis situasi untuk mengetahui arah konsep ilmu ,2) identifikasi masalah, sebagai dasar perlunya rekonstruksi berdasarkan kebutuhan siswa, 3) prioritas masalah, sebagai acuan pilihan masalah yang sangat urgen diantara berbagai masalah, 4) tujuan, yaitu sebagai harapan pelaksanaan rekonstruksi pada peningkatan pembelajaran 5) pemecahan masalah, 6) operasional, 7) pelaksanaan tindakan, dan 8) evaluasi. Dengan mengembangkan materi permasalahan pada kehidupan sehari-hari yang membutuhkan praktikum virtual berbasis PhET. Materi energi dan perubahannya yang sudah dianalisis, dipadukan dengan indikator problem solving sehingga terbangun materi yang dapat dioperasikan secara PhET simulasi. Adapun konsep materi yang dianalisis berupa energi, hukum kekekalan energi, pembagian energi, jenis energi dan perubahannya, hubungan energi dan kerja, sumber-sumber energi, serta pemanfaatan energi dalam kehidupan sehari-hari.

Berdasarkan pemahaman konsep di atas, maka peserta didik dapat sangat mudah mengoperasikan simulasi PhET berdasarkan masalah yang diberikan. Demikian juga mengoperasikannnya pada solusi yang diinginkan jika dihubungkan dengan permasalahan yang sering ditemukan pada kehidupan sehari-hari. Melalui operasional simulasi PhET, antara analisis konten terintegrasi indikator problem solving, yang dibangun dalam sebuah materi IPA pada konteks energi dan perubahannya, dapat dengan mudah dioperasikan sesuai simulasi $\mathrm{PhET}$ yang sudah dilatih dan dipahamkan. Dengan demikian konsep pembelajaran IPA berbasis praktikum dapat tercapai dengan penggunaan simulasi virtual Laboratorium berbasis PhET (Clark \& Chamberlain, 2014).

Pendekatan berbasis MER-PS dengan PhET ini juga memancing siswa untuk ikut aktif belajar, karena harus melakukan operasi simulasi pembelajaran, dan mengisi LKPD sesuai dengan proses pembelajaran yang dilakukan.

Tabel 1 menunjukkan beberapa contoh materi PhET-Problem Solving berdasarkan permasalahannya, solusi, cara pengoperasian PhET dan kesimpulan.

Berdasarkan pemaparan permasalahan yang ditemukan dalam kehidupan sehari-hari berkaitan konteks energi dan perubahannya seperti, (1) dampak debit air yang mempengaruhi kekuatan air tenjun sehingga berdampak pada pasokan listrik sekitarnya. Selain itu, (2) pemanfaatan alam sekitar sebagai sumber energi alternatif, (3) sumber energi alternatif yang dapat digunakan masyarakat apabila sumber energi fossil sudah habis, (4) mengetahui sumber energi alternatif yang yang diketahui dan yang ada di lingkungan masyarakat, (5) serta mengetahui hal apa saja yang dipahami siswa tentang sumber energi yang pernah didengar, namun belum tentu terdapat pada lingkungannya. 
Analisis Konten (Energi dan Perubahannya)

Energi (E) : adalah kem ampuan untuk melakukan usaha atau kerja

2. Hukum Kekekalan Energi : Energi tidak dapat diciptakan dan tidak dapat dimusnahkan, hanya dapat berubah dari energi yang satu ke energi yang lain

Energi dapat dibagi menjadi energi potensial dan energi kinetik

4. Energi mempunyai berbagai jenis seperti energi kimia energi panas, energi gerak, energi cahaya, energi bunyi, energi listrik. Energi-energi tersebut dapat berubah satu sam a lain.

Semakin besar energinya semakin besar kerja atau usaha yang dihasilkannya

Sumber energi terbagi atas : air, udara(angin), surya, uap, batu bara, minyak bum i, panas bum i, dll
(Analisis Konten Perubahan Energi)

7. Energi kimia dapat berubah menjadi energi gerak, dan energi gerak dapat berubah menjadi energi listrik, energi listrik dapat berubah menjadi energi cahaya, energi panas, dan energi gerak dan sebagainya

8. Sebagaimana dengan sumber energi yang diketahui, maka alam Indonesia menyediakan segala sumber tersebut dan untuk digunakan untuk proses kehidupan seluruh masyarakat.

9. Energi dalam pemanfaatannya dapat dikategorikan pada energi terbarukan dan energi tidak terbarukan. Energi terbarukan merupakan sumber utama yang perlu dikembangkan saat in 1

Beberapa Permasalahan yang ditemukan :

M inyak bumi sebagai pembangkit tenaga listrik

A ir sebagai sumber pembangkit listrik

Batubara sebagai sumber pembangkit tenaga listrik

Indikator Problem
Solving
1. Analisis Situasi
2. Identifikasi Masalah
3. Prioritas Masalah
4. Tujuan
5. Pemecahan Masalah
6. Operasional
7. Pelaksanaan Tindakan
8. Evaluasi

1. Masuk melalui internet pada laman :

https://phet.colorado.edu/sims/html/energy-forms-andchanges/latest/energy-forms-and-changes in.html

2. Pilih model virtual lab energi dan perubahannya

3. Pelajari cara mengoperasikannya dari panduan atau arahan guru IPA (LKS)

4. Lakukan praktikum virtual berdasarkan indikator problem solving yang diajukan oleh guru.

5. Kerjakan tes yang diberikan setelah pembelajaran virtual lab selesai.

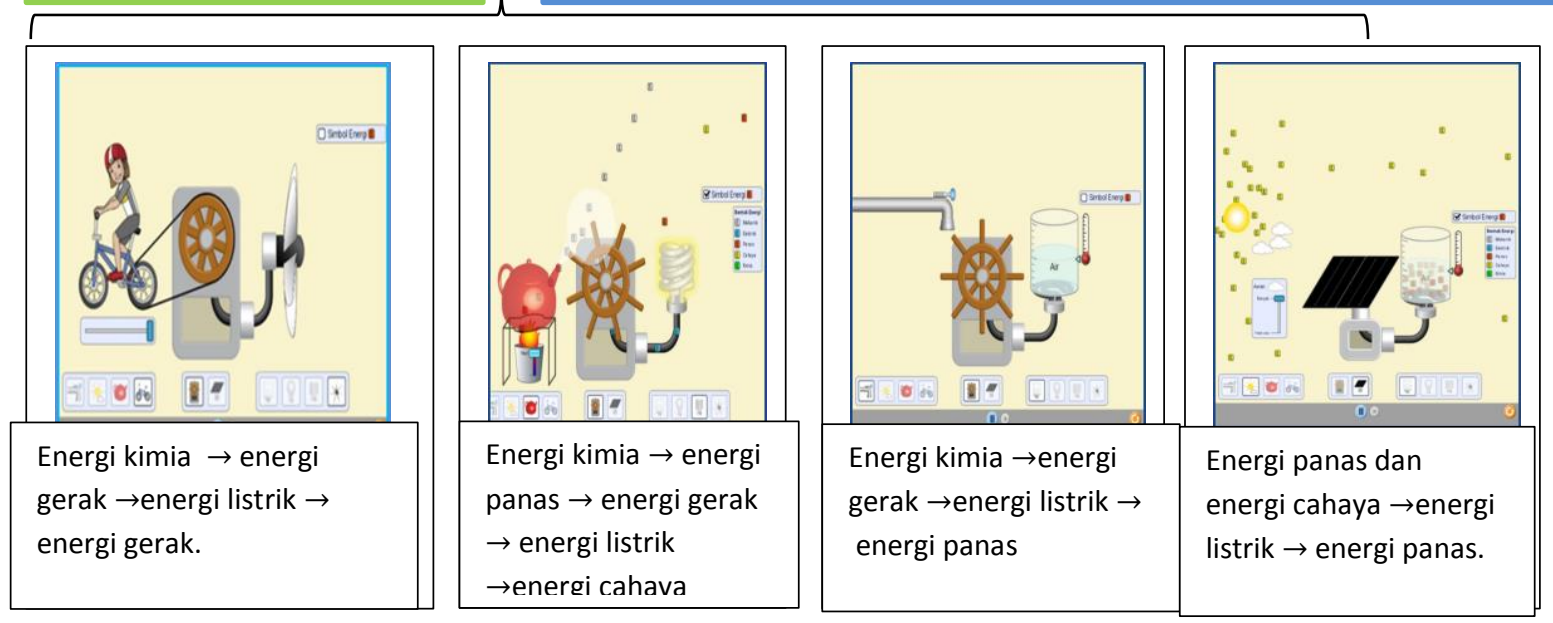

Gambar 2.Rekonstruksi Model Pembelajaran IPA Konteks Energi dan Perubahan Berbasis PhET-PS 
Tabel 1. PhET berbasis indikator Problem Solving

\begin{tabular}{l} 
Permasalahan \\
\hline 1. Air terjun Sigura-gura di \\
sumatera utara digunakan \\
untuk penyedia pasokan \\
listrik (PLTA) di sekitar \\
provinsi sumatera utara, \\
namun terkadang pasokan \\
listrik yang ada dari PLN \\
tersebut tidak berjalan \\
dengan maksimal. Apa \\
yang terjadi sehingga terjadi \\
permasalahan tersebut?
\end{tabular}

Solusi

Tentu solusi yang diperlukan adalah debit air terus dijaga dengan baik, karena bila debit air berkurang maka air yang kecil akan mengurangi tenaga air terjun.

\begin{tabular}{lr}
\multicolumn{3}{l}{ Pengoperasian } \\
Bila dalam sebuah \\
praktikum, \\
bagaimanakah anda \\
melakukan \\
operasional \\
simulasi? & Perhatikan \\
petunjuk r pada & gambar $\quad$ sebagai \\
pengendali & air, \\
semakin kencang air \\
jatuh dan debit yang \\
semakin besar pula \\
tenaga air sehingga \\
dapat rarar memutar \\
turbin.
\end{tabular}

turbin.

Sama seperti dengan praktek virtual PhET simulasi

digunakan mengalir dapat digunakan sebagai sumber penggerak turbin dengan membuat air terjun buatan. Air terjun buatan mempunyai fungsi seperti air terjun alami. Seberapa besar air terjun yang dihasilkan . yang dapat dimanfaatkan untuk dapat menghasilkan listrik. Apakah yang perlu dilakukan masyarakat?

3. Saat ini bahan bakar fossil sudah semakin berkurang untuk bahan bakar minyak, sehingga saat ini sedang diusahakan pengembangan energi terbarukan. Seperti matahari? Mengapa matahri sangat diperlukan sebagai alternatif sumber energi?

4. Tentu anda sering mendengar sumber energi terbarukan. Misalnya tenaga surya, air, panas bumi (tenaga uap). Beberapa jenis pembangkit listrik di Indonesia terdiri dari PLTA, PLTD, PLTS, PLTU.PLTN,PLTB.

Energi-energi tersebut adalah sumber energi untuk pembangkit pasokan listrik Negara bagaimanakah cara kerja PLTU?

5. Apakah anda pernah mendengar kincir angin? Angin juga merupakan
Energi terbarukan merupakan energi yang karena tidak pernah habis. Suatu ketika energi fossil berupa minyak bumi akan habis.

Sebagaimana prinsip kerja air terjun, uap air berupa panas bumi dapat menggerakkan turbin, dan selanjutnya dapat menghidupkan dynamo dan mengalirkan arus kebutuhan masyarakat luas.

Perhatikan

pengoperasian pada gambar. Panas matahari diserap oleh sel surya dan dialirkan sebagai sumber tenaga listrik untuk kehidupan.

Perhatikan pengoperasian PhET dalam gambar simulasi, dimana uap air dari panas air dapat memutar kincir dihubungkan ke dinamo mengalirkan arus listrik yang dapat sangat potensial saat ini, listrik keseluruh menyalakan lampu.

\section{Kesimpulan}

Ketika air hujan biasanya debit air berlimpah sehing air terjun memiliki tenaga yang besar, dan turbin akan berputar dengan maksimal sehingga listrik teraliri dengan baik.Debit air semakin kecil akibat musim kemarau, terjadi penggundulan hutan dihulu sehingga mempengaruhi debit air, maka kekuatan air terjun berkurang dan pasokan listrik juga kecil.

Air sungai dapat dibentuk menjadi air terjun buatan untuk mendapatkan tenaga air yang dapat memutar turbin dan selanjutnya menghidupkan dynamo aliran listrik, untuk dipergunakan kebutuhan hidup.

Sinar matahari adalah salah satu sumber energi yang dapat digunakan untuk membang- kitkan listrik atau sering disebut pembangkit listrik tenaga surya

Uap air atau panas bumi merupakan alternatif sumber energi yang dapat dirubah menjadi energi pembangkit listrik atau disebut dengan pembangkit listrik tenaga uap.
Sebagaimana diketahui, Dapat dilakukan Angin salah satu bila angin diarahkan seperti prinsip baling- sumber energi yang pada kincir, maka kincir baling. Atau seperti sangat baik, dan 


\begin{tabular}{|c|c|c|c|}
\hline Permasalahan & Solusi & Pengoperasian & Kesimpulan \\
\hline $\begin{array}{lr}\text { sumber energi terbarukan } \\
\text { yang tidak } & \text { habis. } \\
\text { Bagaimana prinsip } & \text { kerja } \\
\text { angina } & \text { dalam } \\
\text { membangkitkan } & \text { energi } \\
\text { lain?. } & \end{array}$ & $\begin{array}{l}\text { akan berputar dan } \\
\text { selanjutnya kincir angina } \\
\text { yang berputar dapat } \\
\text { menggerakkan dynamo } \\
\text { untuk mengalirkan listrik } \\
\text { keperluan kehidupan. }\end{array}$ & $\begin{array}{l}\text { ilustrasi simulasi di } \\
\text { atas, bahwa air dapat } \\
\text { digantikan dengan } \\
\text { angin dan kincir air } \\
\text { digantikan kincir } \\
\text { angin. }\end{array}$ & $\begin{array}{l}\text { selalu tersedia seperti } \\
\text { matahari atau uap air, } \\
\text { panas bumi, dan ait } \\
\text { terjun. Energi ini } \\
\text { merupakan energi } \\
\text { terbarukan yang } \\
\text { sangat dibutuhkan. }\end{array}$ \\
\hline
\end{tabular}

\section{Validasi Model}

Hasil nilai validasi expert judgement pada kriteria sesuai (S), Perbaikan (P), dan tidak sesuai (TS), pada konten materi berdasarkan keterkaitan material dan indikator PhET-PS, kesesuaian ilustrasi dan gambar, dan keakuratan penilaian latihan dan soal ditunjukkan pada tabel 2 .

Berdasarkan validasi modul dihasilkan keterkaitan antara material dan PhET-PS sebesar 92,66, kesesuaian ilustrasi dan gambar 78, dan keakuratan penilaian latihan dan soal 86,6 , serta rata-rata nilai validasi adalah 85,75 menunjukkan bahwa model sangat layak digunakan, dan menjadi dasar bahan ajar yang digunakan untuk implementasi pembelajaran IPA konteks energi dan perubahannya berbasis PhET-problem solving, sebagaimana telah ditunjukkan pada tabel 1 .

Tabel 2. Validasi Expert Judgement Model PhET-PS

\begin{tabular}{|c|c|c|c|c|c|c|c|c|c|}
\hline \multirow[t]{3}{*}{$\begin{array}{l}\text { Konten } \\
\text { materi }\end{array}$} & \multicolumn{2}{|c|}{$\begin{array}{l}\text { Keterkaita } \\
\text { antara } \\
\text { material } \\
\text { PhET-PS } \\
\end{array}$} & dan & \multicolumn{3}{|c|}{$\begin{array}{l}\text { Kesesuaian } \\
\text { illustrasi } \\
\text { and } \\
\text { gambar }\end{array}$} & \multicolumn{3}{|c|}{$\begin{array}{l}\text { Keakuratan } \\
\text { penliaian, } \\
\text { latihan, dan } \\
\text { Soal. }\end{array}$} \\
\hline & \multicolumn{9}{|c|}{ \% Score from Validator } \\
\hline & S & $\mathrm{P}$ & $\begin{array}{l}\mathrm{T} \\
\mathrm{S} \\
\end{array}$ & $\mathrm{S}$ & $\mathrm{P}$ & $\begin{array}{l}\mathrm{T} \\
\mathrm{S} \\
\end{array}$ & $\mathrm{S}$ & $P$ & $\begin{array}{l}\mathrm{T} \\
\mathrm{S} \\
\end{array}$ \\
\hline $\begin{array}{l}\text { Sumber } \\
\text { Energi }\end{array}$ & 86 & 14 & 0 & $\begin{array}{l}7 \\
7\end{array}$ & $\begin{array}{l}2 \\
3 \\
\end{array}$ & 0 & 85 & 15 & 0 \\
\hline $\begin{array}{l}\text { Perubahan } \\
\text { Energi }\end{array}$ & 96 & 4 & 0 & $\begin{array}{l}7 \\
0 \\
\end{array}$ & $\begin{array}{l}3 \\
0\end{array}$ & 0 & 80 & 20 & 0 \\
\hline $\begin{array}{l}\text { Implement } \\
\text { asi Energi }\end{array}$ & 96 & 4 & 0 & $\begin{array}{l}8 \\
7 \\
\end{array}$ & $\begin{array}{l}1 \\
3 \\
\end{array}$ & 0 & 95 & 5 & 0 \\
\hline Rata-rata & $\begin{array}{l}92,6 \\
6 \\
\end{array}$ & $\begin{array}{l}7,3 \\
4 \\
\end{array}$ & $\mathbf{0}$ & $\begin{array}{l}7 \\
8\end{array}$ & $\begin{array}{l}2 \\
2\end{array}$ & $\mathbf{0}$ & $\begin{array}{l}86, \\
6\end{array}$ & $\begin{array}{l}13, \\
4\end{array}$ & $\mathbf{0}$ \\
\hline
\end{tabular}

\section{Pelaksanaan Implementasi Pembelajaran}

Sintak Pembelajaran IPA konteks energi dan perubahannya dibagi dalam 3 tahapan yaitu, tahap pendahuluan, Inti, dan Penutup. Pada kelas konvensional metode pembelajaran yang diberikan adalah seperti biasa, sedangkan kelas eksperimen diberikan model pembelajaran PhET-Problem Solving. Sebelum pembelajaran terlebih dahulu diberikan tes (pretes) untuk mengetahui kondisi awal pemahaman konsep siswa terhadap materi energi dan perubahannya. Setelah pembelajaran selesai diberikan juga tes (Postes), untuk mengetahui kondisi pemahaman konsep setelah pembelajaran terlaksana. Evaluasi tes soal bentuk pilihan berganda, yang disesuaikan dengan kisikisi soal yang diberikan.

\section{Perolehan Nilai N-Gain Siswa SMPN 13}

Hasil nilai pretes dan postes partisipan siswa kelas kontrol dan kelas eksperimen dianalisis dengan uji N-Gain. Hasil N-gain kelas kontrol pada kategori tinggi dan sedang sebesar $27 \%$ dan $46 \%$, sedang kelas eksperimen sebesar $30 \%$ dan $70 \%$. $\mathrm{Hal}$ ini menunjukkan persentase perolehan $\mathrm{N}$-gain kategori tinggi dan sedang kelas eksperimen lebih besar dibandingkan kelas kontrol yang ditunjukkan pada gambar 3, demikian juga persentase perolehan nilai postes kelas eksperimen (K.EKSP) lebih tinggi dari kelas kontrol (K.KTRL) (gambar 3).

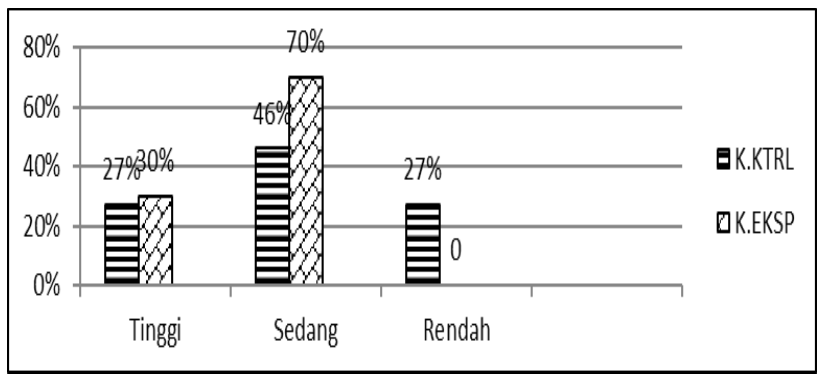

Gambar 3. Persentase Kategori Perolehan N-Gain Siswa

Berdasarkan hasil analisis perolehan nilai postes dan $\mathrm{N}$-gain kelas eksperimen, membuktikan kemampuan daya nalar siswa terhadap konsep materi jauh lebih baik dengan menggunakan model pembelajaran PhET-Problem Solving dibanding dengan model konvensional. Hal ini terkait dengan materi IPA yang telah direkonstruksi berbasis problem solving dan dihubungkan pada aplikasi teknologi virtual PhET, serta secara langsung dioperasikan siswa pada saat pembelajaran. Selain itu adanya ketertarikan siswa saat operasi PhET, hal ini dikarenakan menjadi model pembelajaran yang 
baru pada siswa. Hal ini membuktikan bahwa pendekatan model berbasis kebutuhan siswa, cenderung dapat meningkatkan kualitas pembelajaran (Duit, 2007). Model pembelajaran konvensional dengan fasilitas pembelajaran yang kurang maksimal dan dimungkinkan membosankan siswa, sehingga mempengaruhi pemahaman konsep siswa. Seiring dengan itu, persentase perolehan nilai postes kelas eksperimen sangat baik, baik, dan cukup mencapai $93 \%$ dan kelas kontrol $73 \%$, (gambar 4).

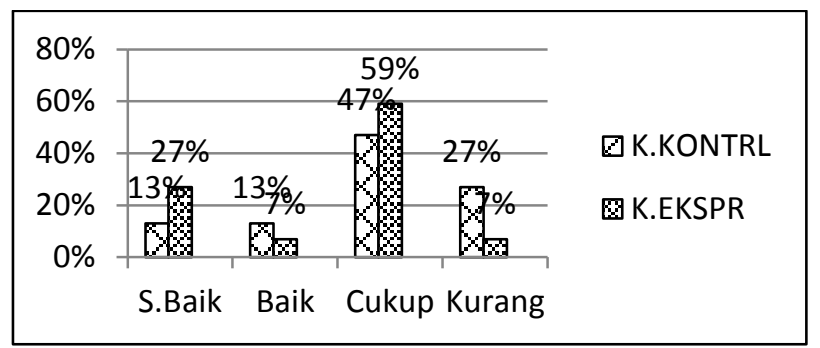

Gambar 4. Persentase kategori perolehan nilai siswa

\section{Analisis 2 Sampel Saling Bebas}

Analisis dua sampel saling bebas t-test SPSS 21 antara nilai postes kelas kontrol dan kelas eksperimen menunjukkan perbedaan yang signifikan dimana sig.(2-tailed $<0,5$ ) (tabel 3).Hal ini menunjukkan terjadi pola penerimaan yang berbeda setelah model pembelajaran IPA secara teknologi virtual dapat terkoneksi dengan materi IPA konteks energi dan perubahannya yang telah terrekonstruksi sesuai kebutuhan siswa.

Tabel 3. Analisis sampel uji independen

\begin{tabular}{llll}
\hline \multicolumn{4}{l}{ Sample Kolmogorov-Smirnov Test } \\
\hline $\begin{array}{l}\text { Normal } \\
\text { Parameters }\end{array}$ & Asymp.Sig.(2-tailed) & $\mathrm{N}$. \\
\hline Control Class & $.718>.05$ & Normal & 15 \\
\hline Experiment Class & $.884>.05$ & Normal & 15 \\
\hline Independent Sample Test & & \\
\hline Sig.(2-tailed) & Control & Experiment & \\
& Class & Class & \\
\hline & $.012<.05$ & $.013<.05$ \\
\hline
\end{tabular}

\section{Hasil Tanggapan/Skala Sikap Siswa}

Perolehan skala sikap siswa kelas eksperimen siswa SMPN 13 Jayapura ditinjukkan tabel 4. Berdasarkan analisis tanggapan siswa kelas eksperimen terhadap model pembelajaran menunjukkan model pembelajaran IPA berbasis PhET-PS sangat diperlukan oleh siswa, karena memberikan manfaat yang sangat baik terhadap peningkatan kemampuan daya nalar siswa. Selain itu variasi model pembelajaran dapat memacu belajar siswa, karena tidak membosankan dan juga akan meningkatkan semangat siswa. Dengan sendirinya diharapkan dapat meningkatkan pemahaman konsep dan nilai hasil belajar siswa. Kesemuanya tanggapan yang diberikan berkisar antara sangat positif dan positif.

Tabel 4. Skala sikap/ Tanggapan siswa SMPN 13 kelas eksperimen

\begin{tabular}{|c|c|c|c|c|c|}
\hline \multirow[t]{2}{*}{ No. } & \multirow[t]{2}{*}{ Pernyataan } & \multicolumn{4}{|c|}{$\%$ Tanggapan } \\
\hline & & STP & $\mathrm{TP}$ & SP & $\mathrm{P}$ \\
\hline 1. & $\begin{array}{l}\text { Perlunya Pembelajaran } \\
\text { Berbasis PhET-PS }\end{array}$ & - & - & 60 & 40 \\
\hline 2. & $\begin{array}{l}\text { PhET-PS Memberi manfaat } \\
\text { pada PBM IPA }\end{array}$ & - & - & 66 & 34 \\
\hline 3. & $\begin{array}{l}\text { PhET-PS masih media } \\
\text { pembelajaran yang } \\
\text { disekolah }\end{array}$ & 6 & - & 40 & 31 \\
\hline 4. & $\begin{array}{lr}\text { Terjadi } & \text { peningkatan } \\
\text { kemampauan } & \text { eksperimen } \\
\text { virtual } & \end{array}$ & 6 & - & 60 & 34 \\
\hline 5. & $\begin{array}{l}\text { Siswa Mampu Mengikuti } \\
\text { PBM berbasis PhET-PS }\end{array}$ & 6 & - & 60 & 34 \\
\hline 6. & $\begin{array}{l}\text { PhET-PS membuat siswa } \\
\text { terpacu belajar }\end{array}$ & - & - & 73 & 27 \\
\hline 7. & $\begin{array}{l}\text { Siswa Merespon Model } \\
\text { Pembelajaran PhET-PS }\end{array}$ & - & - & 53 & 47 \\
\hline 8. & $\begin{array}{l}\text { Model PhET-PS dapat } \\
\text { meningkatkan semangat } \\
\text { belajar }\end{array}$ & - & - & 73 & 27 \\
\hline 9. & $\begin{array}{l}\text { Keinginan selalu terlibat } \\
\text { aktif mengoperasikan PhET- } \\
\text { PS }\end{array}$ & - & - & 73 & 27 \\
\hline 10. & $\begin{array}{l}\text { Harapan siswa melaui PBM } \\
\text { berbasis PhET dapat } \\
\text { meningkatkan Nilai IPA }\end{array}$ & - & - & 80 & 20 \\
\hline Rata & Rata \% Tanggapan siswa & 6 & - & 63,8 & 30,2 \\
\hline
\end{tabular}

\section{PENUTUP}

Berdasarkan hasil penelitian yang telah dilakukan, maka disimpulkan bahwa melalui rekonstruksi model pembelajaran materi IPA pada konteks materi dan perubahannya berbasis Physics Eduction Technology-problem solving (PhET-PS) layak digunakan. Kelayakan rekonstruksi modul kimia, dapat dilihat dari nilai valiasi konten materi, konten media, dan konten bahasa melalui uji validasi expert judgement dengan persentasi ratarata $85,75 \%$ dengan kriteria penggunaan model 
sangat layak. Peningkatan pemahaman konsep dapat dilihat dari nilai $\mathrm{N}$-gain siswa. Hasil analisis nilai \% $\mathrm{N}$-Gain kategori sedang dan tinggi kelas kontrol dan eksperimen masing-masing 27\%, 46\%, dan 30\%, 70\%. Berdasarkan uji sampel independen tes, Sig.(2-tailed) 0,012 $<0,05$ dan 0,13 $<0,05$, menunjukkan terdapat perbedaan rata-rata yang signifikan pada dua kelompok. Sedangkan tanggapan siswa kelas eksperimen terhadap implementasi model adalah pada kriteria sangat positf $63,8 \%$ dan positif $46 \%$. Peningkatan pemahaman konsep yang lebih tinggi pada kelompok eksperimen membuktikan model PhETPS lebih efektif dibandingkan model pembelajaran konvensional.

Peranan interaksi langsung siswa pada pengoperasian simulasi PhET materi IPA yang dirancang dalam sebuah permasalahan yang ditemukan dalam kehidupan sehari-hari, telah meningkatkan daya nalar siswa menengah negeri 13 Jayapura terhadap materi tersebut. Selain itu siswa dapat secara berulang melakukan operasional simulasi, bila dirasa belum maksimal memahami praktikum tersebut. Hal ini juga yang membedakan praktikum virtual berbasis PhET-PS lebih unggul dibandingkan proses praktikum konvensional, sebagaimana kita ketahui bahwa praktikum konvensional sangat jarang dilakukan pengulangan praktikum, diakibatkan beberapa pertimbangan seperti ketidakcukupan bahan dan alat yang digunakan, ketidak cukupan waktu praktikum disebabkan harus diulang kembali dari awal.

Melalui aplikasi model ini, diharapkan konsep materi IPA yang lain berbasis praktikum, dapat dikembangkan melalui peran teknologi simulasi seperti PhET yang dihubungkan dengan indikator-indikator berpikir tingkat tinggi lainnya

\section{DAFTAR PUSTAKA}

Anderson, L.W., \& Krathwohl (2010). Pembelajaran, Pengajaran, dan A. Y. P. P. 185-200. Pembelajaran, Pengajaran, dan Asesmen. Yogjakarta. Pustaka Pelajar (pp. 185-200).

Avalos, B. (2011). Teacher Professional Development in Teaching and Teacher
Education Over Ten Years. Teaching and Teacher Education Journal., 27, 10-20.

Bransford, J., Brophy S., \& Williams, S. (2000). When Computer Technologies Meet The Learning Sciences: Issues and Oppoertunities. Journal of Applied Develop Mental Psychology, 21(1), 59-84.

Cathlene T.B. \& Vida A.A. (2018). Exploring the Effect of PhET Interactive Simulation-Based Activities on Students' Performance and Learning Experiences in Electromagnetism. Journal of Multidisciplinary Research, 6(2), 121-131.

Clark, T. M., \& Chamberlain, J. M. (2014). Use of a PhET interactive simulation in general chemistry laboratory: Models of the hydrogen atom. Journal of Chemical Education. https://doi.org/10.1021/ed400454p

Doloksaribu, F., Mudzakir A.,Sholihin H., \& S. F. (2014). Model Education Reconstruction (MER) Bahan Ajar Penelitian Laboratorium Konteks Zeolit Berbasis Problem Solving Decision Making (PSDM). Jurnal Penelitian Pendidikan UNNES, 31(2). https://doi.org/https://dx.doi.org/10.15294/jp p.v31i2.5694

Doloksaribu, F., \& T. (2020). The Reconstruction Model of Science Learning based PhETProblem Solving. International of Journal on Studies, 3(1), 37-47.

Duit, R. (2007). Duit, R. (2007). Internationally: Domains of Research, 3(1), 3-15. Eurasia Journal of Mathematics, Science \& Technology Education.

Duit, R., Gropengießer, H., Kattmann, U., Komorek, M., \& Parchmann, I. (2012). The model of educational reconstruction - a framework for improving teaching and learning science. In Science Education Research and Practice in Europe: Retrosspective and Prospecctive. https://doi.org/10.1007/978-94-6091-900-8

Habibi H, Jumaidi J, M. M. (2020). Phet simulation as means to trigger the creative thinking skills of physics concepts. Intternational Journal of Emerging Technologies in Learning, 15(16), 166-172. 
Hake, R. R. (1999). Analyzing charge /gain score.

Kriek, J., \& Stols, G. (2010). Teachers' beliefs and their intention to use interactive simulations in their classrooms. South African Journal of Education.

https://doi.org/10.15700/saje.v30n3a284

Louis Major, Gill Francis, M. T. S. (2021). The effectiveness of technology supported personalised learning in low and middle income countries a meta analysis. British Journal of Educational Technology, 1-30.

Moore, E. B., Chamberlain, J. M., Parson, R., \& Perkins, K. K. (2014). PhET interactive simulations: Transformative tools for teaching chemistry. Journal of Chemical Education.

https://doi.org/10.1021/ed4005084

Nursa'adah, E., Liliasari, Mudzakir, A., \& Barke, H. D. (2018). The model of educational reconstruction: Students' conceptual knowledge on solid state chemistry domain. Jurnal Pendidikan IPA Indonesia. https://doi.org/10.15294/jpii.v7i2.14297

Roger Cooke. (2014). Validating Expert Judgement with classical Model.

Sallis Edward. (2006). Total Quality Management in Education. Journal of Education Technology, 37(2), 312-313. https://dx.doi.org/10.1111/j.14678535.2006.00602_7.x

Sari, D. K., Permanasari, A., \& Supriyanti, F. M. T. (2017). Profile of students' creative thinking skills on quantitative project-based protein testing using local materials. Jurnal Pendidikan IPA Indonesia. https://doi.org/10.15294/jpii.v6i1.9516
Sari, D. P., Tjandrakirana, T., \& Kuntjoro, S. (2018). Applying Science Learning PhET Simulation to Improve Process Skill and Knowledge Aspect of Junior High School Student. JPPS (Jurnal Penelitian Pendidikan Sains).

https://doi.org/10.26740/jpps.v7n2.p14961500

Stiggins, R. (2005). Formative for problem solving: A path to succsess in standards-based schools". Journal Phy Delta Kappan., 87(7), 324-328.

Sugiyono. (2011). Metode Penelitian Pendidikan (Pendekatan Kuantitatif, Kualitatif, $(R \& D)$.Penerbit Alfabeta. Bandung.

Sundayana, R. (2014). Statistika penelitian pendidikan.

Supurwoko, S., Cari, C., Sarwanto, S., Sukarmin, S., Budiharti, R., \& Dewi, T. S. (2017). Virtual Lab Experiment: Physics Educational Technology (PhET)Photo Electric Effect for Senior High School. International Journal of Science and Applied Science: Conference Series. https://doi.org/10.20961/ijsascs.v2i1.16750

Tuysuz, C. (2010). The Effect of the Virtual Laboratory on Students' Achievement and Attitude in Chemistry. International Online Journal of Educational Sciences. 